\title{
Contos medievais e "modernos": das reuniões em torno das lareiras aos contos de fadas
}

David Sales Barbosa

\section{Resumo}

Este trabalho analisa contos da Baixa Idade Média e da Idade Moderna provenientes da Inglaterra, da Itália, da França e da Alemanha, narrativas advindas de antologias como o Pentamerone, de Giambattista Basile, os Contos de Mamãe Gansa, de Charles Perrault, e os Contos de Grimm, dos irmãos Jacob e Wilhelm Grimm. A pesquisa tem como objetivo explicitar, nas narrativas, elementos medievais que transpassaram o medievo ou que influenciaram contos redigidos no estopim da "modernidade", além de buscar apresentar as diferenças e semelhanças entre os contos e perceber, por meio de uma análise discursiva e da transição dos períodos históricos, os retoques e as mudanças de discursos, de acordo com local, época e interesses que as redes discursivas de tais períodos buscavam propagar.

Palavras-chave: Contos - Idade Média - Discurso. 
Desde a infância, somos cercados por histórias de princesas enclausuradas em castelos, lobos que perseguem garotinhas na floresta, jovens que sofrem com a orfandade nas mãos de irmãs e madrastas malvadas, entre outras; histórias que são, ainda, permeadas por bruxas perversas, ogros, fadas, encantamentos etc. Na maioria das vezes, príncipes encantados ou outros personagens aparecem surpreendentemente e direcionam a um final em que os protagonistas triunfam de forma mágica e encantadora. Devido à proximidade que temos desde cedo com essas narrativas, presentes em tantas culturas, passa-nos despercebido que tais contos/histórias infantis/contos de fadas já sofreram uma gama de transformações em suas estruturas e que possuem uma historicidade ainda pouca explorada, o que faz pairar uma nebulosidade no que concerne ao seu estudo e à sua pesquisa.

Muitos estudiosos já buscaram analisar os contos de diversos ângulos e perspectivas, cada um com suas próprias ferramentas e objetivos específicos. Psicanalistas, antropólogos, filólogos, pedagogos, folcloristas, literatos, entre outros, embasados na metodologia de suas respectivas ciências, buscaram (e ainda buscam), de maneira gradual, uma compreensão do universo dos contos. Seria impensável e equivocado não reconhecer a contribuição desses pesquisadores e, mais ainda, duvidar da sua erudição, mas é necessário apontar que, talvez pela rudeza do oficio, alguns estudiosos limitam-se, na contemporaneidade, a regressar em termos teóricos e metodológicos ao século XIX e a parte do XX - mais especificamente, ao estopim do cientificismo no campo das ciências humanas - e apenas traçar panoramas lineares, em uma sucessão quase perfeita de acontecimentos. Assim, analisam os contos como meros pacientes num divã, às vezes rechaçando sua carga histórica devido ao fascínio das simbologias existentes e, por fim, estabelecendo um padrão para a leitura das narrativas como se existisse uma fórmula única e universal. O fato é que poucas análises historiográficas têm sido realizadas sobre o tema.

Em uma perspectiva de longa duração ${ }^{\mathrm{I}}$, buscamos analisar o período de transição da Baixa Idade Média para a época moderna, até meados do século XIX, debruçando-nos em contos provenientes da literatura oral e escrita da Itália, da França e da Alemanha. Ao analisar e comparar as antologias, procuramos uma compreensão das narrativas, explicitando o contexto histórico

I Conceito de história de longa duração de Fernand Braudel, segundo o qual características ou resquícios de um determinado período histórico perpetuam-se e transpassam períodos posteriores (BRAUDEL, I992). 
dos contos, assim como os retoques e as mudanças de discursos ${ }^{2}$ que sofreram dependendo dos interesses do interlocutor. Além disso, a análise transcende comparações ao mostrar um mundo medieval que transpassou o medievo por meio da oralidade e eternizou-se nas narrativas, resistindo aos mais diversos retoques ao passar da tradição oral para as páginas das antologias de Giambattista Basile ${ }^{3}$, de Charles Perrault ${ }^{4}$ e dos irmãos Grimm ${ }^{5}$.

Mesmo nos tempos modernos e na época contemporânea, as narrativas exalam características de uma sociedade de séculos outrora e apresentam, nos textos e contextos, um mundo pertencente aos tempos medievais. Por que, na primeira versão escrita de Chapeuzinho Vermelho, coletada da oralidade francesa no século XVII, Ghapeuzinho é vorazmente devorada pelo lobo? $\mathrm{Na}$ mesma história, na versão da antologia dos irmãos Grimm (de meados do século XIX), ela é devorada junto com sua avó, resgatada da barriga do lobo por um caçador que nem existia na versão francesa de Perrault e ambas as personagens vivem "felizes para sempre". Por quê? Desde Perrault, as narrativas começaram a ser atenuadas, mas por que mudaram os discursos? Por que os organizadores de antologias buscaram suavizar e "adocicar" contos que, na oralidade, se vistos de um ponto de vista contemporâneo, pareceriam sanguinários, violentos e cruéis? A que, necessariamente, essas reelaborações de discursos buscavam atender? Seria a ideia da infância, já em pleno final do século XVII? Ou a demanda de uma sociedade que estava prestes a adentrar o "iluminado" mundo do esclarecimento?

Alguns pontos teóricos e historiográficos merecem ser relevados. Vejamos: é extremamente perigoso balizar e tentar definir marcos decisórios de transição entre períodos históricos, pois não há nada que defina de maneira consistente que estamos deixando um período e iniciando outro. As demarcações são totalmente subjetivas, sem contar a longevidade das mentalidades, que permanecem adentrando os períodos históricos seguintes, subvertendo e contrariando

2 Conceito de discurso de Michel Foucault, que entende discurso como um objeto/acontecimento histórico no qual um enunciado pode ser dito ou não num determinado período no tempo. A rede discursiva refere-se aos elementos que formam uma cadeia de discursos, que legitimam uma verdade e constroem o sujeito numa relação de poder (FOUCAULT, I989).

3 O napolitano Giambattista Basile foi responsável por coletar contos na Itália e transcrevê-los no papel em sua antologia conhecida como Pentamerone.

4 No século XVII, Charles Perrault coletou contos da oralidade francesa e transcreveu-os em papel. Ele foi responsável por transcrever, com pioneirismo, a primeira versão de Chapeuzinho Vermelho da tradição oral francesa para as páginas de sua antologia conhecida como Contos de Mamãe Gansa.

5 Jacob e Wilhelm Grimm coletaram contos na Alemanha e publicaram-nos em sua antologia conhecida na Alemanha por Kinder- und Hausmarchen e, no Brasil, por Contos de Grimm. 
aquele novo período histórico no qual estão inseridas. Mas, enfim, embora precisássemos dessas balizas cronológicas, mal sabíamos que isso geraria uma série de impasses, e muito menos o sabia Jacob Burckhardt ${ }^{6}$. Se já é difícil fazer essas demarcações em outros campos da história, mais difícil é nos que envolvem a cultura e a oralidade. Em fins da Idade Média, percebemos uma literatura oral proveniente de séculos. Contada tanto nos castelos pelas classes mais favorecidas quanto pelos trabalhadores e camponeses em suas cabanas, a literatura foi sendo difundida, carregando traços do período e narrando um mundo extremamente medieval. O problema se inicia pela questão das fontes das fontes escritas, para sermos mais precisos -, pois não há uma versão escrita de forma integral em documentos medievais de Chapeuzinho Vermelho ou do Pequeno Polegar, por exemplo, mas é possível que essas histórias já circulassem na oralidade camponesa medieval há séculos e tenham sobrevivido até serem coletadas e transcritas em papel por Charles Perrault, narrativas que carregam consigo características sociais, econômicas e culturais da Idade Média e também de uma extensão dela pelo período que conhecemos como Idade Moderna.

E se Charles Perrault tivesse nascido antes do final do século XV ou qualquer outro que vivesse em tal período tivesse recolhido tais narrativas da oralidade e as transcrito para o papel? Saberíamos, enfim, que as narrativas eram mesmo medievais? E se os contos tivessem sido coletados um dia após o marco estabelecido entre a Idade Média e a Idade Moderna? Teríamos, neste último caso, um documento mais medieval ou moderno? E se a Idade Média tivesse seu fim cronológico decretado somente no fecho do século XVII? A primeira publicação dos Contos da Mamãe Gansa de Charles Perrault, em I697, seria, nesse casso, uma narrativa medieval? Ao que parece, na teoria, somos ou queremos ser revolucionários, mas, na prática, ainda estamos com metodologias do cientificismo do século XIX. Abandonamos o conceito de verdade histórica, mas o documento (escrito) ainda parece ter uma força surpreendente e inexpugnável. Historiadores, parece que precisamos rever os nossos conceitos.

$\mathrm{Na}$ questão teórica, ao tomar os contos como objeto de análise, vemo- los como discursos produzidos numa rede discursiva em um determinado período no tempo, seja na oralidade, seja em adaptações para versões escritas. As mudanças das narrativas são aplicadas e podem ser explicadas por meio de "verdades" criadas e legitimadas pelos embates de poder em meio à rede que as produziu.

6 Historiador suíço responsável por balizar os períodos históricos e nomeá-los em meados do século XIX (Gf. BURGKHARDT, I96I). 
Durante a Idade Média, surgiu uma literatura que narrava contos fantásticos e maravilhosos que fugiam do real e do cotidiano. Como exemplo dessa literatura, podemos citar a novela de cavalaria, que começou a florescer a partir do século XII. Tal gênero enquadra-se no que alguns pesquisadores consideram "cultura de elite", mas essa divisão de culturas parece não fazer tanto (ou nenhum) sentido nesse contexto, pois as novelas de cavalaria se popularizaram, inclusive em outras línguas que não o latim, o que tecnicamente contraria teorias que sustentam padrões de uma literatura erudita, restrita e heterogênea. Vejamos a análise de Robert Darnton (I986, p. 3I-32):

Apesar da obscuridade que cerca as origens dos romances de cavalaria, as canções de gesta e os fabliaux, parece que boa parte da literatura medieval bebeu da tradição oral popular, e não o contrário. A "Bela Adormecida" apareceu num romance arturiano do século XIV e "Ginderela" veio à tona em Propos rustiques de Noel du Fail, de I547, livro que situou as origens dos contos nas tradições camponesas e mostrou como eles eram transmitidos [...]

Por outro lado, eclodiu uma literatura que foi difundida de forma escrita e oral. Era um tipo de manifestação literária que não necessitava de muitas regras. As narrativas eram construídas em cima de temas ligados ao cotidiano, explicitando as mazelas sociais que a sociedade enfrentava, contrariando e denunciado as injustiças sociais por meio do enredo. Possuíam um caráter cômico, às vezes subversivo, e extremamente moralizador. Era a literatura de exemplo, na qual se inseriam os fabliaux.

Alguns contos da antologia de Perrault são curtos e engraçados e cada um possui uma moral que, ao mesmo tempo que contraria regras de conduta contemporâneas, adverte e edifica valores sociais. O que parece é que os fabliaux serviram de fontes para Charles Perrault escrever Mamãe Gansa. Talvez tenhamos neles um ponto de conexão entre o medievo e os tempos modernos. Nelly Novaes Coelho (2010, p. 99-100) também sustenta isso em suas análises:

A Pele de Asno, embora tenha sido retirada de um "fabliau" tem um ancestral em Straparola que registra um caso de amor incestuoso, que por sua vez deriva de uma fonte oriental [...] Lembramos que o "Fabliau" de onde Perrault tirou Grisélidis já constava no Decameron de Boccaccio e também aparece nas Histórias de Proveito e Exemplo de Trancoso ("Constância de Grizela").

Além de literatos, historiadores também sustentam a tese de uma perpetuação dos contos medievais na Idade Moderna, entre eles Robert Darnton (I986, p. 3I): 
Evidências escritas provam que os contos existiam antes de ser concebido o "folclore", neologismo do século XIX. Os pregadores medievais utilizavam elementos da tradição oral para ilustrar argumentos morais. Seus sermões transcritos em coleções de "Exempla" dos séculos XII ao XV referem-se às mesmas histórias que foram recolhidas, nas cabanas dos camponeses, pelos folcloristas do século XIX.

Que os contos retratavam o imaginário medieval, isso é evidente, mas o que esses contos que sobreviveram até a modernidade têm a mais para nos dizer? Se, por um lado, as antologias de Charles Perrault e a dos Irmãos Grimm retratam narrativas seguindo o mesmo modelo das canções de cavalaria, que se refugiavam em um mundo mágico e oposto à realidade social, por outro lado tratam de forma implícita (ou mesmo explícita) a realidade da vida além dos castelos: a vida no campo, a árdua vida dos camponeses. Isso geralmente é retratado de uma forma ou de outra nos contos. Hilário Franco Júnior (200I, p. I34) descreve as dificuldades que os camponeses enfrentavam:

Nas cabanas dos camponeses, as finas paredes de barro impediam menos ainda a entrada do frio, que não podia ser combatido com tapeçarias ou lareiras, muito caras. O fogão colocado no centro da casa ficava aceso o dia todo, cumprindo também essa função. Ainda para enfrentar o frio, era comum que as pessoas dormissem muito próximas umas às outras e que naquele mesmo cômodo, separados ou não por um tapume, fossem colocados os animais da família, cujo calor corporal aquecia as pessoas.

No conto Pequeno Polegar da antologia de Mamãe Gansa de Charles Perrault, a alta taxa de natalidade e a escassez de alimentos são escancarados, relatando a vida de um casal de lenhadores à beira da miséria. É o que podemos constatar no seguinte fragmento:

Era uma vez um lenhador e uma lenhadora que tinham sete filhos, todos meninos [...] Eles eram paupérrimos, e os sete filhos os deixavam num aperto enorme, porque nenhum deles ainda podia ganhar a vida [...] Num ano de poucas colheitas, a carestia de alimentos foi tão grande que aquela pobre gente resolveu se desfazer dos filhos [...] (PERRAULT, 20I2, p. 77).

Perante a dor dos pais por observarem os seus filhos passando fome por dias dentro de casa, a alternativa para os camponeses era livrar-se de sua prole. Talvez, dessa forma, o duplo sofrimento seria atenuado. Em outras narrativas, essa prática de abandonar os filhos na floresta também é descrita. Em 
João e Maria (Grimm I5)7, conto coletado pelos irmãos Grimm pouco mais de um século depois de Perrault, um casal de crianças é abandonado no meio da floresta pelos mesmos motivos. Pelo que parece, a fome era mesmo temida, afinal era um atalho para outro medo medieval: a morte. E, conforme Darnton (Ig86, p. 49), aterrorizou a França.

O tom casual sugere como se tornara comum a morte de crianças, no Início da França Moderna. Perrault escreveu seu conto em meados de I69o, no auge da pior crise demográfica do século XVII - período em que a peste e a fome dizimavam a população do norte da França, quando os pobres comiam carniças atiradas nas ruas por curtidores, quando eram encontrados cadáveres com capim na boca e as mães "expunham" os bebês que não podiam alimentar, para eles adoecerem e morrerem. Abandonando seus filhos na floresta, os pais do Pequeno Polegar tentavam enfrentar um problema que acabrunhou os camponeses muitas vezes, nos séculos XVII e XVIII - o problema da sobrevivência durante um período de desastre demográfico.

Mas, antes de serem eternizados no papel, como e onde esses contos eram narrados? Bem, ao cair da tarde as famílias se reuniam em torno da lareira, que tinha uma dupla função: além de espantar o frio, abria espaço para a veillée. Enquanto as mulheres fiavam e os homens consertavam suas ferramentas, as histórias eram narradas oralmente ao redor da lareira para todos os membros da casa.

[...] Noel du Fail [...] fez a primeira descrição por escrito de uma importante instituição francesa, veillée, reunião junto à lareira, à noitinha, quando os homens consertavam suas ferramentas e as mulheres costuravam, escutando as histórias que seriam registradas pelos folcloristas trezentos anos depois e que já duravam séculos. Pretendessem elas divertir os adultos ou assustar as crianças, como no caso de "Chapeuzinho Vermelho", as histórias pertenciam sempre a um fundo de cultura popular, que os camponeses foram acumulando através dos séculos, com perdas notavelmente pequenas (DARNTON, I986, p. 32).

Durante a Renascença, com a invenção da imprensa na segunda metade do século XV, a escrita e, por conseguinte, os livros obtiveram uma enorme di-

7 Os contos de Grimm são classificados em uma ordem padrão. Portanto, podemos localizar o conto em qualquer edição dos Contos de Grimm sem muita dificuldade por meio da classificação numérica. Todavia, a versão traduzida em português pela editora Itatiaia não seguiu a ordem utilizada. Seguimos a ordem orientando-nos por uma tradução em inglês dos Contos Completos dos Irmãos Grimm (GRIMM; GRIMM, I972). 
fusão. No campo literário, os contos, que há séculos vinham sendo narrados oralmente ao calor das lareiras, começaram a ganhar versões escritas e a receber uma série de alterações em suas estruturas. É importante salientar que o acesso à leitura não ocorreu de forma generalizada. Portanto, as narrativas puderam sobreviver intactas ou, pelo menos, com poucas perdas, sobretudo afastadas das cidades, longe do Renascimento, na cultura oral que circulava afastada das áreas urbanas, nas cabanas dos camponeses.

Se, por um lado, na oralidade as versões dos contos eram permanências do mundo medieval, por outro, na "cultura erudita", o medievo também estendeu seus domínios. A literatura foi adaptada e transcrita no estopim do Renascimento e no limiar dos tempos modernos em moldes advindos da tão desprezada Idade Média. Nesse contexto, o Renascimento ou a sua vulgarização não passa de uma contradição, pois ele se utilizou, em partes, de elementos e estruturas medievais na literatura.

É inegável que as narrativas foram atenuadas ao passar da tradição oral para as páginas de Mamãe Gansa. Mas nem tudo foi atenuado. Tais contos não buscavam ainda atender aos ideais da infância, como muitos pensam. Eles já poderiam até ser narrados para as crianças, mas o público não era esse ainda. Isso foi invenção dos séculos posteriores: diferenciar a infância como uma fase singular e única. As narrativas eram específicas para os adultos e, como não havia ainda a ideia de infância, sobretudo no campo, na oralidade os "pequenos" talvez ouvissem atemorizados, na íntegra, a crueza e brutalidade presente nos contos. Darnton (I986, p. 27) pontua que, especificamente na França, "os camponeses não precisavam de um código secreto para falar sobre tabus [...] as outras histórias da Mamãe Ganso têm as mesmas características de pesadelo”.

No começo do século XIX, entre I8I2 e I822, os alemães Jacob e Wilhelm Grimm, mais conhecidos como os irmãos Grimm, lançaram os Kinder- und Hausmarchen, publicados em dois volumes. As narrativas propuseram resgatar as raízes do folclore e da cultura alemã. Ao serem redigidas no papel, elas poderiam ser mais bem preservadas, conforme os próprios objetivos e concepções dos Grimm. Na coleta dos contos, apesar de os irmãos terem tentado ser o mais fiéis possível à transcrição das histórias orais, houve, sim, muitas reelaborações de discursos, muitas vezes de forma gradual com as reedições dos Kinder- und Hausmarchen.

No século XIX, então, a rede discursiva buscava atender, de certa forma, a três necessidades do período: à construção do conceito de infância, à fortificação do nacionalismo germânico e aos ideais literários do movimento romântico do século XIX, calcado nas ideias humanistas do progresso humano e 
na ascensão da sociedade. Tanto é que quase todo os contos de Grimm terminam com finais de triunfo e esplendor, mas somente para os personagens que fazem o "bem". Já os opositores, terminam em sofrimento e desgraça.

Enfim, narrando contos de encantamentos, maravilhosos e repletos de seres místicos, com um forte teor maniqueísta, os contos de Grimm, assim como outras antologias precedentes, fincaram base para a construção dos chamados "contos de fadas", que se propagaram e se dispersaram até o tempo presente, adaptando-se aos ideais presentes por onde e por quem passavam. Estes, apesar de terem recebido uma série de enxertos e retoques, ainda narram um mundo repleto de costumes e cenários de um mundo medieval e também moderno.

Vejamos: uma madrasta como a de Branca de Neve (Grimm 53) pergunta ao seu espelho mágico: "Dize a pura verdade, dize, espelho meu: há no mundo mulher mais bela do que eu?" (GRIMM; GRIMM, I994, p. 358); uma feiticeira grita para o alto de uma torre: "Rapunzel, Rapunzel! Desce os teus cabelos" (GRIMM; GRIMM, I994, p. 323) (Grimm I2); uma Gata Borralheira, no baile, corre desesperadamente ao ouvir "o relógio soar a primeira badalada da meia-noite quando achava que ainda nem eram onze horas" (PERRAULT, 2012, p. 65). Desvinculados de um olhar científico, enxergamos essas histórias como narrativas que servem apenas para divertir as crianças. Nada mais seriam do que meras estórias. Porém, tratá-las de tal modo é relegar um objeto de análise histórico e fértil, e é isso que a Antropologia, a Literatura, a História e outras ciências têm buscado, nas últimas décadas, desmitificar, decifrando e compreendendo o universo dos contos a partir do seguinte questionamento: o que tais narrativas têm a nos dizer? Uma pergunta difícil de ser respondida, mas nada custa tentar.

Se tem algo que encontramos nas narrativas, sejam elas italianas, sejam francesas ou alemãs, são as temidas madrastas e irmãs malvadas, que perseguem seus/suas enteados(as) e irmãos(ãs), respectivamente, com os(as) quais não possuem um relacionamento familiar nada pacífico. Os(as) enteados(as) são praticamente excluídos(as) do âmbito familiar, obrigados(as) a fazer as mais distintas tarefas domésticas. Em Gata Borralheira, a protagonista sofre nas mãos da madrasta, que "deu-lhe as ocupações mais humildes da casa: era ela que lavava a louça e as escadas, que limpava o chão dos quartos da senhora e das senhoritas suas filhas. A moça dormia bem no alto da casa, no sótão, num colchão ordinário de palha [...]" (PERRAULT, 20I2, p. 59). Na versão francesa, ela dormia, pelo menos, na palha. Na alemã, "[...] quando a infeliz já não se aguentava de cansaço, não permitiam que ela deitasse na cama: tinha de dormir na cozinha mesmo, no meio das cinzas" (GRIMM; GRIMM, 
I994, p. 20). No conto O irmão e a irmã (Grimm II), a questão da orfandade ressurge. Dessa vez, dois irmãos planejam uma fuga de casa para acabar com o sofrimento decorrente da morte da mãe e do caos após o novo casamento do pai: "[...] nossa madrasta nos espanca todos os dias e, quando chegamos perto dela, nos expulsa a pontapés. O cachorro come melhor do que nós, pois frequentemente lhe dão um pedaço de carne" (GRIMM; GRIMM, I994, p. 29). Outra órfã era "[...] obrigada a trabalhar muito, comer pouco e andar mal vestida. Todos os dias tinha de sentar-se junto do poço, a margem da estrada, fiando, fiando, até seus dedos sangrarem" (GRIMM; GRIMM, I994, p. 268) (Grimm 24). Mas por que o sofrimento dos órfãos era narrado aos extremos e com todos os detalhes?

É fato que as madrastas assolaram as famílias no mundo medieval e, também, no mundo moderno. Ao observarmos o sentido ${ }^{8}$ dessa palavra na análise discursiva percebermos que, nos contos, "madrasta" tornou-se um sinônimo de perigo. Elas surgem como aliadas do "mal", demonstrando todas as formas possíveis de repulsa aos seus enteados, o que justifica o sofrimento deles. Mas por qual razão podemos encontrá-las com tanta frequência nessas histórias? Temos que relacionar o texto com o contexto histórico, pois, em tais períodos, havia muitas mulheres que morriam durante complicações no parto devido à má alimentação, o que poderia aumentar a probabilidade de um pai se casar novamente após a morte da esposa, cedendo, assim, espaço para as madrastas. É o que vemos nas análises de Hilário Franco Júnior (200I, p. 28):

Como mostrou o estudo de Bullough e Campbell (22: I980. 3I7-325), até o século X ou XI a mulher ingeria pequena quantidade de ferro, que seu organismo necessita em proporção maior que o do homem devido à menstruação, à gravidez e à lactação. Portanto, a anemia feminina era generalizada na Alta Idade Média, daí a maior propensão das mulheres a certas doenças. Com a introdução de leguminosas na dieta e uma presença mais assídua de carne, peixe, ovos e queijo, a mortalidade feminina diminuiu. Tal fato teve ampla repercussão, contribuindo até mesmo para a valorização social da mulher.

Apesar de ter ocorrido uma queda da mortalidade feminina a partir do século X, ela não cessou de maneira generalizada. Perdurou ainda por séculos.

8 "Para a análise do discurso, não existe um sentido a priori, mas um sentido que é construído, produzido no processo de interlocução, por isso deve ser referido as condições de produção (contexto histórico-social, interlocutores...) do discurso. Segundo Pêcheux, o sentido de uma palavra muda de acordo com a formação discursiva a que pertence.” (BRANDÃO, 2004, p. IO9-IIO). 
Podemos ver como os contos mudam ao longo do tempo, dependendo, também, do lugar e dos interesses com os quais foram redigidos. A estrutura do conto Sol, Tália e Lua, de Giambattista Basile, é muito semelhante à de Bela Adormecida no Bosque de Perrault e à de Bela Adormecida dos irmãos Grimm. Temos o mesmo conto, mas com retoques franceses e alemães. Basile pouco se preocupou em atenuar elementos considerados subversivos às morais contemporâneas de seu tempo na narrativa do Pentamerone. Tália, após ser encantada e cair num sono profundo por tempo indeterminado, é deixada em uma torre num castelo até que, um dia, um rei, em uma de suas caçadas, entra no castelo e encontra-a dormindo. Ao vê-la, "sentiu-se excitado por admirar tamanha beleza, suspendeu-a em seus braços e carregou-a para a cama, onde colheu os primeiros frutos do amor [...] depois de nove meses, Tália deu à luz um par de crianças, um menino e uma menina [...]" " (BASILE, I893, p. 520, tradução nossa). É quase impossível, na contemporaneidade, imaginarmo- nos narrando tal história para o público infantil. Isso, certamente, evidencia que os tempos e os costumes mudaram, pois certos discursos dependem das circunstâncias históricas do tempo para serem ditos.

Contudo, quando Perrault redigiu sua Bela Adormecida no Bosque, esses elementos já nem mais existiam. O autor extinguiu uns e retocou outros. $\mathrm{Na}$ versão de Basile, a avó pretende se livrar dos próprios netos pedindo ao cozinheiro que ele "[...] os degolasse e preparasse com eles diversas iguarias para o pobre pai" ${ }^{\circ}$ (BASILE, I893, p. 522, tradução nossa). Na versão de Perrault, a avó é uma ogra que deseja também destruir seus netos, mas devorando-os. E, em ambas as narrativas, a avó malvada tem um final brutal: na versão italiana, o rei "ordenou que a rainha deveria ser lançada no fogo que ela havia preparado para Tália"II (BASILE, I893, p. 524, tradução nossa); na versão francesa, a avó prepara uma tina repleta de "[...] sapos, víboras, cobras e serpentes [...]" (PERRAULT, 2012, p. 35) para a Bela Adormecida, mas ela é que acaba dentro da tina, sendo devorada pelos animais. Já na versão alemã dos Grimm do século XIX, todas as atrocidades contidas no conto nas versões precedentes foram retiradas e a narrativa foi romantizada (devido ao movimento literário Romântico do século XIX), perdendo diversos elementos e ganhando outros.

9 "[...] he felt his blood course hotly through his veins in contemplation of so many charms, and he lifted her in his arms, and carried her to a bed, whereon he gathered the first fruits of love [...] now Talia was delivered after nine months of a couple of beautiful creatures, one a boy and the other a girl [...]."

Io "[...] Told the cook to slay them, and prepare several tasteful dishes for her wretched husband [...]."

II "[...] he commanded that the queen should be cast into the fire which she had prepared for Talia." 
Portanto, os discursos mudaram para atender às necessidades específicas de cada tempo e dos interlocutores, tanto para requintar os contos, como fez Perrault, como para construir e buscar atender ao conceito de infância, como fizeram os irmãos Grimm. O fato é: os contextos históricos mudam, os interesses mudam e as narrativas, também.

A Zezolla de Basile foi a base para a Gata Borralheira de Perrault e para a Cinderela dos Grimm. No conto italiano, Zezolla fica insatisfeita com sua madrasta e planeja matá-la, induzida pela governanta, que arma um plano: Zezolla deveria pedir à madrasta um vestido velho que se encontrava num baú; enquanto a madrasta estivesse debruçada sobre o baú, vasculhando pelo vestido, a governanta pede que Zezolla, que estaria segurando a tampa, "deixe cair a tampa e o pescoço dela será partido" ${ }^{2}$ (BASILE, I893, p. 56). Na versão dos Grimm,

[...] as irmãs são castigadas por sua perversidade, ficando cegas o resto da vida", o contrário da versão de Perrault, na qual "Gata Borralheira", mesmo após todas as maldades que suas irmãs fizeram, "Borralheira, que era tão boa quanto era bela, trouxe as duas irmãs para morar no palácio e casou-as naquele dia mesmo com dois grandes nobres da corte. (PERRAULT, 20I2, p. 66).

Robert Darnton (I986, p. 29) não exagera ao dizer que "os contos retratavam um mundo de brutalidade nua e crua". A saber: quando a princesa, em Bela Adormecida no Bosque de Perrault, quer dar uma surra no filho por ele ter sido malcriado e sua sogra, que é uma descendente de ogro, deseja devorar os netos; ou quando a Chapeuzinho Vermelho do autor francês é devorada pelo lobo; ou quando um irmão manda matar o outro, como em O Nabo (Grimm I46); ou quando uma criança morre perambulando na floresta após ser expulsa de casa pela própria mãe, como em As Fadas (Perrault); ou quando um pai quer se casar com a própria filha, como em $O$ Bicho Peludo (Grimm 65). Trata-se de casos de violência, antropofagia, assassinato, sofrimento, incesto etc. Tudo isso configura uma teia de significados pertencentes a contextos históricos de épocas e culturas de séculos atrás, que, de algum modo, conseguiram resistir por meio das narrativas ao migrarem da oralidade ao redor das lareiras para as transcrições para o papel, elaboradas por um napolitano e um francês no século XVII e por dois alemães no século XIX, até se consolidarem no "século do cientificismo", na efervescência da consolidação da ideia de infância, como literatura infantil ou, simplesmente, como contos de fadas. 


\section{Referências}

BASILE, G. Il Pentamerone; or the tale of the tales. Translation by Richard Burton. London: Henry and Co, I893.

BRANDÃO, H. H. N. Introdução à análise do discurso. 2. ed. rev. Campinas, SP: Editora da UNICAMP, 2004.

BRAUDEL, Fernand. História e Giências sociais. A longa duração. In:

Escritos sobre a história. 2. ed. São Paulo: Perspectiva, I992, p. 4I-78.

BURCKHARDT. J. Reflexões sobre a história. Rio de Janeiro: Zahar Editores, I96I.

BURKE, P. Cultura popular na Idade Moderna. Tradução de Denise Bottmann. 2. ed. São Paulo: Companhia das Letras, I989.

COELHO, N. N. Panorama histórico da literatura infanto/juvenil: das origens indo-europeias ao Brasil contemporâneo. São Paulo: Manole, 2010.

DARNTON, R. O grande massacre de gatos: e outros episódios da história cultural francesa. Rio de Janeiro: Graal, I986.

FOUCAULT, M. A ordem do discurso: aula inaugural no Collége de France, pronunciada em 2 de dezembro de I970. São Paulo: Edições Loyola, 2012.

Microfísica do poder. 8. ed. Rio de Janeiro: Graal, I989.

FRANGO JUNIOR, H. A Idade Média: nascimento do Ocidente. São Paulo: Brasiliense, 2OOI.

GRIMM, J.; GRIMM W. Contos de Grimm. Tradução de David Jardim Jr. Belo Horizonte/Rio de Janeiro: Villa Rica, I994 (Coleção Grandes Obras da Cultura Universal, v. I6).

The complete Grimm's fairytale. Translation by Margaret Hunt. New York: Pantheon, I972.

LE GOFF, J. Em busca da Idade Média. Rio de Janeiro: Civilização Brasileira, 2005.

PERRAULT, G. Contos da Mamãe Gansa. Porto Alegre: L\&PM, 2012.

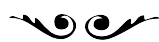

David Sales Barbosa é graduado em História pelo Centro Universitário do Norte.

davidıoosales@hotmail.com 